\title{
The Choice of the Main Power Components in Electric Traction Converters
}

\author{
Lavinius Sorin Goreci*, Mihaela Popescu** and Ion Tilă* \\ * S.C. INDA SRL, Research\&Development Department, Craiova, România, lavinius.goreci@inda.ro, tila.ion@inda.ro \\ University of Craiova, Faculty of Electrical Engineering, Craiova, Romania, mpopescu@em.ucv.ro
}

DOI: 10.52846/AUCEE.2021.1.05

\begin{abstract}
The choice of the power components of the electric traction converters for autonomous vehicles is a very important aspect in their design. The attention in this paper is first focused on the choice of the DC link capacitor, followed by choice of the IGBT modules, their testing and cooling. Then, the choice of power cables is approached. A dedicated test bench for electric traction converters for autonomous vehicles was designed and achieved. In defining the parameters of the test bench, various possible applications on battery-powered vehicles were taken into account, but also their performances, technical characteristics and functional characteristics. An important share belongs to the integrated propulsion/charging system of the Li-Ion battery developed by the company SC INDA SRL. It is already used in automotive on full-electric trucks and in the battery-powered electric locomotives.
\end{abstract}

Cuvinte cheie: vehicul autonomy, IGBT, condensator de current continuu, invertor, radiator, răcire, MELCOSIM.

Keywords: autonomous vehicle, IGBT, DC link capacitor, inverter, heat sink, cooling, MELCOSIM.

\section{INTRODUCTION}

Currently, high voltage and current IGBTs are state-ofthe-art power electronics modules for the electric traction converters for autonomous vehicles [1-5]. The IGBT itself is part of a complex power kit which includes besides the transistor, input capacitors, laminated bus bars, the cooling system, gate drives etc. For reliable operation the choice of these components is not an easy task considering the technical characteristics of the traction systems.

The best features of a high power IGBT module are closely related to a reliable and high quality protection for IGBT drivers [1]. The attention in [2] is directed towards the connection between a reliable operation of IGBT modules and three important requirements that they have to fulfill: high junction temperature limit, large safe operating area, high current capacity. Methods for obtaining IGBT switching frequency limits are discussed in [3]. A comparison between switching characteristics and losses of IGBT modules for traction applications is studied experimentally in [4]. Reference [5] describes the equations for the power losses evaluation and passive elements design.

The test bench described below includes the designed inverters in the final purpose of a subsidiary contract to the PACETSINEFEN project within the Competitiveness Operational Program, European Regional Development Fund [6]. A block diagram is presented in Fig. 1, where:

TR - three-phase transformer with control sockets;

$\mathrm{R}$ - three-phase rectifier;

INV1, INV2 - three-phase inverters;

$\mathrm{Ct}$ - DC link capacitor;
$\mathrm{CF}$ - braking chopper;

$\mathrm{RF}$ - braking resistor;

MAS1 - asynchronous machine (motor mode);

MAS2 - asynchronous machine (generator mode);

TUi - voltage transducers;

$\mathrm{TC}$ - current transducers;

TG1, TG2 - speed transducers;

TCP - torque transducers;

UCR - electronic control unit.

The testbench consists of two asynchronous machines (MAS1, MAS2) mechanically coupled, the first one operating in motor mode and the second in generator mode. The rated power of each machine is $155 \mathrm{~kW}$ and in short-term overload mode they allow $390 \mathrm{~kW}$. This ensures a wide range of tests with power up to 400 $\mathrm{kW}$.The two asynchronous machines are supplied by two inverters INV1 and INV2 with PWM (pulse width modulation) control and variable frequency according to the operating modes. The two inverters have a classic structure and have a common DC link. The energy consumed by MAS1 in the motor mode is taken from MAS2 which operates in generator mode and motor generator system losses are taken from the power supply

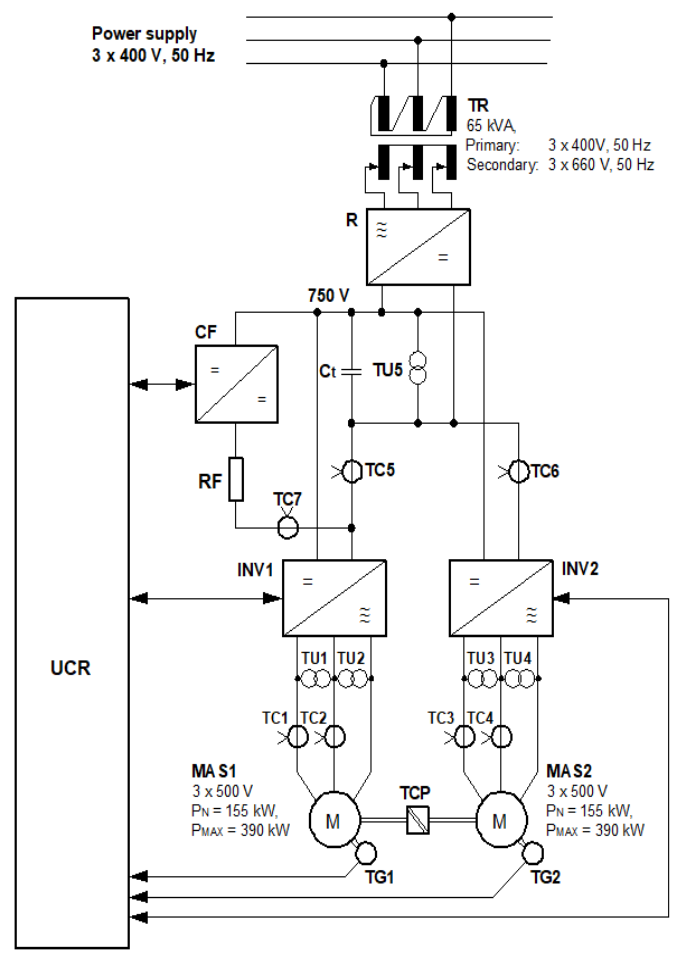

Fig. 1 The block diagram of the test bench.

$(3 \times 400 \mathrm{~V}, 50 \mathrm{~Hz})$ through the transformer TR and rectifier $\mathrm{R}$. For the situation of dynamic regime in the intermediate 
circuit, an RF braking resistor is provided, the current through this resistor being controlled by the $\mathrm{CF}$ Braking Chopper.

The rest of the paper is organized as follows: Section II describe the choice of DC link capacitor. In section III, the main parameters of leading inverter are defined and his section deals with the choice of IGBT modules. It is followed by the IGBT modules verification in Section IV. Section V and VI are related to the choice of the cooling system and the power cables. Finally, some concluding remarks are drawn.

\section{THE CHOICE OF THE DC LINK CAPACITOR}

The following relationships are used to calculate the characteristic data for the inverter that supplies MAS1 [7]:

- $\quad$ Rated power,

$$
S_{\text {NINV1 }}=\frac{P_{1 \text { NMASI }}}{\cos \varphi_{\text {MAS1 }} \eta_{\text {MAS1 }}}=188.6 \mathrm{kVA} \text {, }
$$

where $P_{\text {MASI }}, \cos \varphi_{\text {MASI }}, \eta_{\text {MASI }}$ are the active power, the power factor and respectively the efficiency of machine MAS1.

As can be seen in the block diagram (Fig.1), the direct current intermediate circuit of the inverter INV1 is common with those of the inverter INV2, braking chopper $\mathrm{CF}$ and the filter of rectifier $\mathrm{R}$ and therefore the total capacitance value in the diagram was taken into account for the calculation of the capacitor bank.

To determine the required capacitance value we will consider the following conditions:

- ripple voltage alowed,

$$
U_{R R}=15 \% \cdot U_{C C} ;
$$

For rated voltage $\mathrm{U}_{\mathrm{CC}}=750 \mathrm{~V}$, it results $\mathrm{U}_{\mathrm{RR}}=112.5 \mathrm{~V}$.

- the inverter efficiency,

$$
\eta_{I N V I}=93 \% \text {; }
$$

- The input power of the inverter INV1,

$P_{I N V I}=S_{I N V I}+p_{I N V I}=202 \mathrm{~kW}$,

where $S_{I N V I}, p_{I N V I}$ are the rated power and power losses of the inverter.

To calculate the nedeed capacitance, it can be used the following approached equation [8]:

$$
C_{\text {tcale }}=\frac{P_{R N V 1}}{U_{R R} \cdot\left(U_{C c}-\frac{U_{R R}}{2}\right) f_{R}}=8600 \mu \mathrm{F},
$$

where: $f_{R}$ - the rectifier frequency, $\mathrm{f}_{\mathrm{R}}=300 \mathrm{~Hz}$.

The RMS current through capacitor will be (approached equation) [8]:

$$
I_{\text {CRMS }}=\frac{\mathbb{U}_{R R}}{2 \sqrt{2}} \cdot C_{\text {tcale }} \cdot 2 \cdot \pi \cdot f_{R}=646 \mathrm{~A} .
$$

The nedeed capacitance for the inverter INV1:

$$
C_{I N V 1}=C_{\text {tcalc }}-\left(C_{I N V 2}+C_{C F}+C_{R}\right) \text {, }
$$

where:

$C_{I N V 2}=4380 \mu \mathrm{F}$ - capacitance value of the inverter INV2;
$C_{C F}=1460 \mu \mathrm{F}$ - capacitance value of the braking chopper $\mathrm{CF}$;

$C_{R}=1460 \mu \mathrm{F} \quad$ - capacitance value of the rectifier $\mathrm{R}$.

We obtain $C_{I N V I}=1300 \mu \mathrm{F}$.

Two ZEZ SILKO PVAJP 0 1,8/700 capacitors conected in parallel were selected with the main characteristics:

- rated capacitance $\quad C_{N}=700 \mu \mathrm{F} \pm 10 \%$;

- rated DC voltage $\quad U_{N}=1800 \mathrm{~V}$;

- insulation voltage $U_{i}=4800 \mathrm{~V}$;

- maximum rms current $I_{\max }=150 \mathrm{~A}$;

- operating temperatures $\Theta_{\mathrm{a}}=-25 /+70{ }^{\circ} \mathrm{C}$.

The selection criteria are met as follows:

$$
\begin{gathered}
C_{t} \geq C_{\text {tcalc }} ; \\
U_{N}>U_{C \text { Cmax }} ; \\
I_{C R M S} \geq I_{\text {CRMScalc } .}
\end{gathered}
$$

The inequality (9) results from the fact that all the capacitors in the common DC intermediate circuit are connected in parallel ( 8 capacitors that have the value Imax $\geq 150 \mathrm{~A}$ ), the value of the total current they can supply will add up, exceeding the value resulting from the calculations.

\section{The ChOISE OF THE IGBT Module}

The inverter output voltage is equal with the rated voltage of the electric machine [6].

$$
U_{\text {NINVI }}=U_{\text {NMASI }}=500 \mathrm{~V}_{\mathrm{AC}} .
$$

- The rated current phase of the inverter

Since the windings of the MAS1 electric machine are connected in star, the following results:

$$
I_{\text {NMAS1 }}=\frac{s_{\text {NANV1 }}}{\sqrt{a} \cdot v_{\text {NMAS1 }}}=218 \mathrm{~A},
$$

where: $U_{N M A S I}-$ rated voltage of MAS1.

- Inverter overload power:

$$
S_{\text {SINV1 }}=1,5 \cdot S_{\text {NINV1 }}=283 \mathrm{kVA}
$$

- Inverter overload phase current:

$$
I_{\text {SMAS1 }}=1,5 \cdot I_{\text {NINV1 }}=327 \mathrm{~A} \text {; }
$$

- Inverter supply voltage range:

$$
U_{C C}=600 \div 900 \mathrm{~V}_{\mathrm{CC}} \text {. }
$$

The power transistor shall be chosen with respect to the following relationships:

$$
\begin{gathered}
I_{\text {TAVN }} \cdot k_{S I} \leq I_{\text {ccat }} ; \\
U_{b} \cdot k_{\text {SU }} \leq U_{\text {CEScat }} ; \\
U_{b}=U_{c c} ; \\
I_{\text {TAVN }}=\frac{\sqrt{2}}{\pi} \cdot I_{\text {SMASI }}=147.2 \mathrm{~A} ;
\end{gathered}
$$

where:

$I_{\text {TAVN }}$ - the average rated current through the transistor; 
$I_{\text {c cat }}$ - the maximum permissible average current through the transistor;

$k_{s i} \quad$ - the current safety factor;

$U_{b} \quad$ - the voltage that stresses the transistor in off state;

$U_{C E S \text { cat }}$ - the maximum permissible voltage that stresses the transistor in off state;

$k_{s u} \quad$ - the voltage safety coefficient;

$U_{C C}$ - the intermediate circuit voltage.

Because the inverter is part of a research test bench where control errors may occur or higher power motors can be tested, the coefficients $k_{s u}=1.8$, respectively $\mathrm{k}_{\mathrm{si}}=10$ were chosen resulting:

$$
\begin{gathered}
U_{\text {CES cat }}>1500 \mathrm{~V} ; \\
I_{C_{\text {cat }}}>1500 \mathrm{~A} .
\end{gathered}
$$

The Mitsubishi CM2400HC - 34H IGBT module was preliminarily selected, with the main characteristics:

- capsule with a single IGBT - diode switching device;

- collector emitter voltage - $\mathrm{V}_{\mathrm{CES}}=1700 \mathrm{~V}$;

- $\quad$ direct collector current $\mathrm{I}_{\mathrm{C}}=2400 \mathrm{~A}$;

- module dimensions : 190 x $140 \mathrm{~mm}$.

An extract from the technical specification of this module is shown in Fig. 2. (a) and (b) [9].

\section{TESTING OF THE IGBT MODULE}

Testing was done based on the MELCOSIM Ver 5.4.0 application, developed by Mitsubishi for the selection of its own IGBT modules, arranged in the most common topologies.

MELCOSIM is designed for the calculation of the stationary and dynamic power losses that occur in modules as well as the temperature variation in the junctions of IGBT transistors and diodes in modules, due to both the direct conduction and switching of these semiconductor devices.

The corresponding data obtained for the specific dynamic thermal resistance of the power modules are used for the design, calculation and dimensioning of the heat sink.

\section{A. MELCOSIM Program Description}

The converter type (two or three levels) can be selected from the main screen and then, switching in the screens for input and output data is done. The input-output screens consist of four sections: the module code and type, the specified module property, the input field "Common Conditions" for the converter characteristic data and the output field for the calculation results.

MELCOSIM expects nine entries called "Common Conditions" to be able to calculate power losses and temperature in the junction: modulation strategy, output current Io, DC link $V c c$ voltage, switching frequency $F c$, output frequency $F o$, modulation factor $M$, load power factor $P F s$ and the heat sink temperature measured directly below the $T s$ capsule.

The results field provides the following information: average power losses for IGBT and freewheel diode, divided into static and dynamic parts, total power loss of the module, heat sink temperature, average and maximum temperature in the transistor junction and in the freewheel diode. The graphics output provides the possibility to analyze power losses and temperature in junction by changing one of the application conditions parameters within the specification.

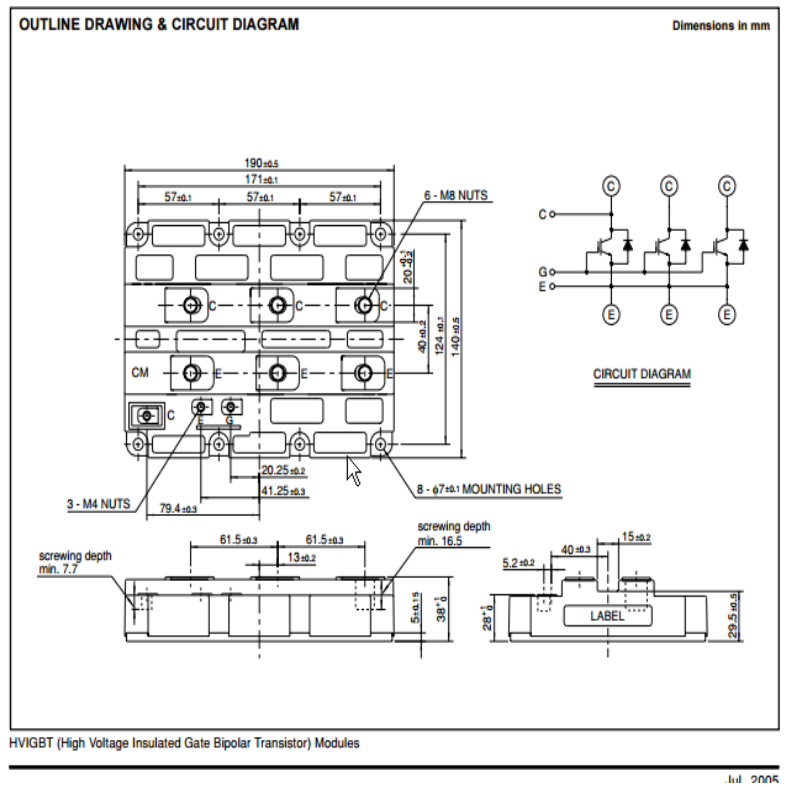

(a)

CM2400HC-34H

HIGH POWER SWITCHING USE INSULATED TYPE

\begin{tabular}{|c|c|c|c|c|}
\hline Symbol & liem & Conditions & Ratings & \begin{tabular}{|l|l} 
Unit \\
\end{tabular} \\
\hline VCES & Collector-emitter voltage & $V_{G E}=0 V, T_{j}=25^{\circ} \mathrm{C}$ & 1700 & $\mathrm{v}$ \\
\hline \begin{tabular}{|l|l|} 
VGES \\
\end{tabular} & Gate-emitter voltage & VCE $=0 V, T \mathrm{~T}=25^{\circ} \mathrm{C}$ & \pm 20 & $\mathrm{v}$ \\
\hline ic & & $T C=80^{\circ} \mathrm{C}$ & 2400 & A \\
\hline ICM & Collector current & (Note 1) & 4800 & A \\
\hline \begin{tabular}{|l|l|} 
IE (Noter \\
\end{tabular} & & & 2400 & A \\
\hline \begin{tabular}{|l|} 
IEM N Neter 2 2 \\
\end{tabular} & Emitter current & (Note 1) & 4800 & A \\
\hline \begin{tabular}{|l|l|}
$\mathrm{PC}$ (Note 3) \\
\end{tabular} & Maximum power dissipation & $T \mathrm{TC}=25^{\circ} \mathrm{C}$. IGBT part & 17800 & w \\
\hline $\mathrm{T}_{\mathrm{T}}$ & Junction temperature & & $-40 \sim+150$ & ${ }^{\circ} \mathrm{C}$ \\
\hline$T_{\infty}$ & Operating temperature & & $-40 \sim+125$ & ${ }^{\circ} \mathrm{C}$ \\
\hline Tstg & Storage temperature & & $-40 \sim+125$ & ${ }^{\circ} \mathrm{C}$ \\
\hline Viso & \begin{tabular}{|l|} 
Isolation voltage \\
\end{tabular} & RMS, sinusoidal, $f=60 \mathrm{~Hz}, \mathrm{t}=1 \mathrm{~min}$. & 4000 & $\mathrm{v}$ \\
\hline tose & $\begin{array}{l}\text { Maximum short circuit pulse } \\
\text { width }\end{array}$ & $\begin{array}{l}V C C=1150 \mathrm{~V}, \mathrm{VCES} \leq 1700 \mathrm{~V}, \mathrm{VGE}=15 \mathrm{~V} \\
\mathrm{~T}_{\mathrm{j}}=125^{\circ} \mathrm{C}\end{array}$ & 10 & us \\
\hline
\end{tabular}

3rd-Version HVIGBT (High Voltage Insulated Gate Bipolar Transistor) Modules

\begin{tabular}{|c|c|c|c|c|c|c|}
\hline \multirow{2}{*}{ Symbol } & \multirow{2}{*}{ Item } & \multirow{2}{*}{ Conditions } & \multicolumn{3}{|c|}{ Limits } & \multirow{2}{*}{ Unit } \\
\hline & & & Min & Typ & $\operatorname{Max}$ & \\
\hline ICES & Collector cut-off current & $V_{C E}=V_{C E S}, V_{G E}=0 V, T_{j}=25^{\circ} \mathrm{C}$ & - & - & 36 & $\mathrm{~mA}$ \\
\hline VGE(m) & $\begin{array}{l}\text { Gate-emitter } \\
\text { threshold voltage }\end{array}$ & IC $=240 \mathrm{~mA}, V_{C E}=10 \mathrm{~V}, \mathrm{~T}_{\mathrm{j}}=25^{\circ} \mathrm{C}$ & 4.5 & 5.5 & 6.5 & v \\
\hline IGES & Gate leakage current & $V_{G E}=V_{G E S}, V_{C E}=0 V, T_{j}=25^{\circ} \mathrm{C}$ & - & - & 0.5 & $\mu \mathrm{A}$ \\
\hline \multirow[b]{2}{*}{ VCE(sat) } & \multirow{2}{*}{\begin{tabular}{|l|l} 
Collector-emitter \\
saturation voltageg
\end{tabular}} & $I C=2400 \mathrm{~A}, V_{G E}=15 \mathrm{~V}, \mathrm{Tj}=25^{\circ} \mathrm{C}$ & - & 2.60 & 3.30 & \\
\hline & & $\mathrm{IC}=2400 \mathrm{~A}, V_{G E}=15 \mathrm{~V}, \mathrm{~T}_{\mathrm{j}}=125^{\circ} \mathrm{C}$ & - & 3.10 & - & V \\
\hline Cies & Input capacitance & \multirow{3}{*}{$\begin{array}{l}\text { VCE }=10 \mathrm{~V}, \mathrm{f}=100 \mathrm{kHz} \\
V G E=O V, T_{\mathrm{j}}=25^{\circ} \mathrm{C}\end{array}$} & - & 210 & - & $\mathrm{nF}$ \\
\hline Coess & Output capacitance & & - & 30.0 & - & $\mathrm{nF}$ \\
\hline Cres & \begin{tabular}{|l|} 
Reverse transter capacitance \\
\end{tabular} & & - & 10.1 & $\begin{array}{cc}- \\
-\end{array}$ & $\mathrm{nF}$ \\
\hline$a_{g}$ & Total gate charge & $V C C=850 \mathrm{~V}, I \mathrm{IC}=2400 \mathrm{~A}, V_{G E}=15 \mathrm{~V}, \mathrm{~T}_{\mathrm{j}}=25^{\circ} \mathrm{C}$ & - & 19.8 & - & $\mu \mathrm{C}$ \\
\hline \multirow{2}{*}{ VEC(Nater) } & \multirow{2}{*}{ Emitter-collector voltage } & $I_{E}=2400 \mathrm{~A}, V_{G_{F}}=0 V_{,} T_{j}=25^{\circ} \mathrm{C}$ & - & 2.30 & 3.00 & $y$ \\
\hline & & IE $=2400 \mathrm{~A}, \mathrm{VG} d \mathrm{~d}=\mathrm{OV}, \mathrm{T}_{\mathrm{T}}=125^{\circ} \mathrm{C}$ & - & 1.85 & - & \\
\hline tolon) & Turn-on delay time & \multirow{3}{*}{ 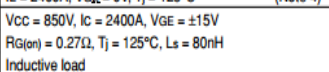 } & - & - & 1.60 & us \\
\hline$t$ & Turn-on rise time & & - & $\begin{array}{c}- \\
\end{array}$ & 1.30 & us \\
\hline Eon & Turn-on switching energy & & - & 810 & - & mivpise \\
\hline tol(ofit) & Turn-off delay time & \multirow{3}{*}{$\begin{array}{l}V C C=850 \mathrm{~V}, \mathrm{LC}=2400 \mathrm{~A}, V_{G E}= \pm 15 \mathrm{~V} \\
R G\left(\text { off) }=0.27 \Omega, T_{j}=125^{\circ} \mathrm{C}, \mathrm{Ls}=80 \mathrm{nH}\right. \\
\text { Inductive load }\end{array}$} & - & - & 2.70 & $\mu \mathrm{s}$ \\
\hline ti & Turn-off fall time & & - & - & 0.80 & $\mu s$ \\
\hline Eotf & Turn-off switching energy & & - & 870 & 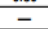 & mylisse \\
\hline tir (10tes) & Reverse recovery time & \multirow{3}{*}{$\begin{array}{l}V C C=850 V, I C=2400 A, V G E= \pm 15 V \\
R G(0)=0.27 \Omega, T_{j}=125^{\circ} C, L s=80 n H \\
\text { (nductive load }\end{array}$} & 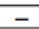 & - & 2.70 & нs \\
\hline 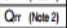 & Reverse recovery charge & & - & 630 & - & $\mu \mathrm{C}$ \\
\hline Erece(lob 2) & Reverse recovery energy & & $\begin{array}{ll}- \\
-\end{array}$ & 330 & - & mylatse \\
\hline
\end{tabular}

ELECTRICAL CHARACTERISTICS

(b)

Fig. 2 Extract from the technical specification of the IGBT module CM2400HC-34H.

All calculation results can be exported to a text file [10]. 


\section{B. IGBT Module Testing in Overload Conditions}

Testing the IGBT module in overload conditions was performed using the MELCOSIM application with the following input data (Fig 3):

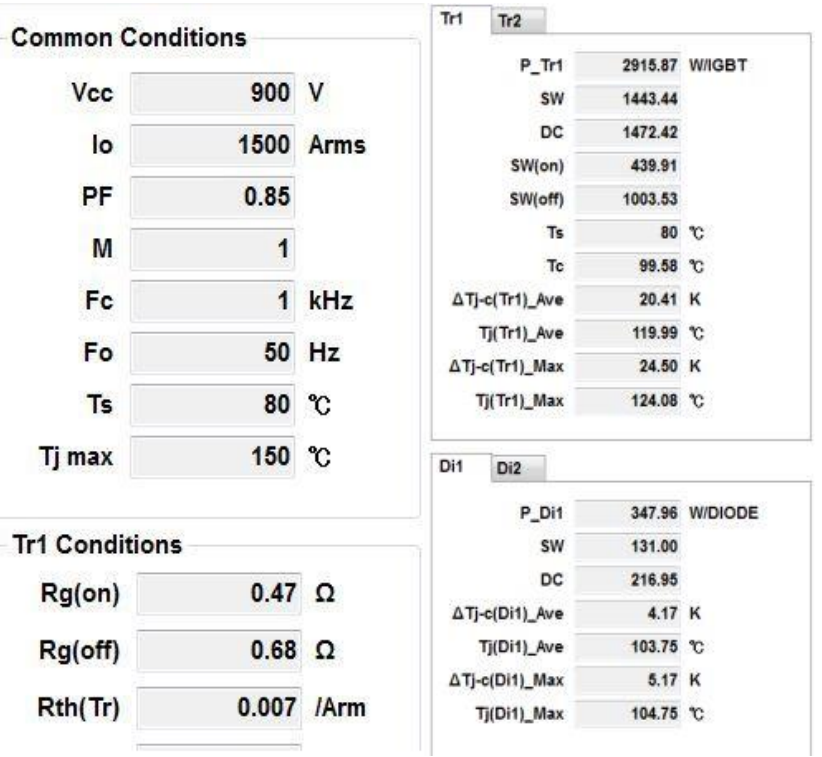

Fig. 3 „Common Condition” and „Result” fields for overload testing.

$V c c$ - the maximum value for the DC circuit voltage, equal to the voltage that stresses the transistor in off state, respectively equal to the voltage limited by the braking chopper $(\mathrm{CF})$ that is set to the value of $900 \mathrm{Vdc}$;

Io - The maximum output current of the asynchronous machine adjusted until the program no longer returns invalid messages.

The valid returned parameters correspond to the most unfavorable situation in which the device can operate for the chosen conditions, resulting:

$$
I_{0} \gg I_{\text {SMASI }} \text {. }
$$

C. IGBT Module Testing for Operation in Rated Conditions (Fig 4):

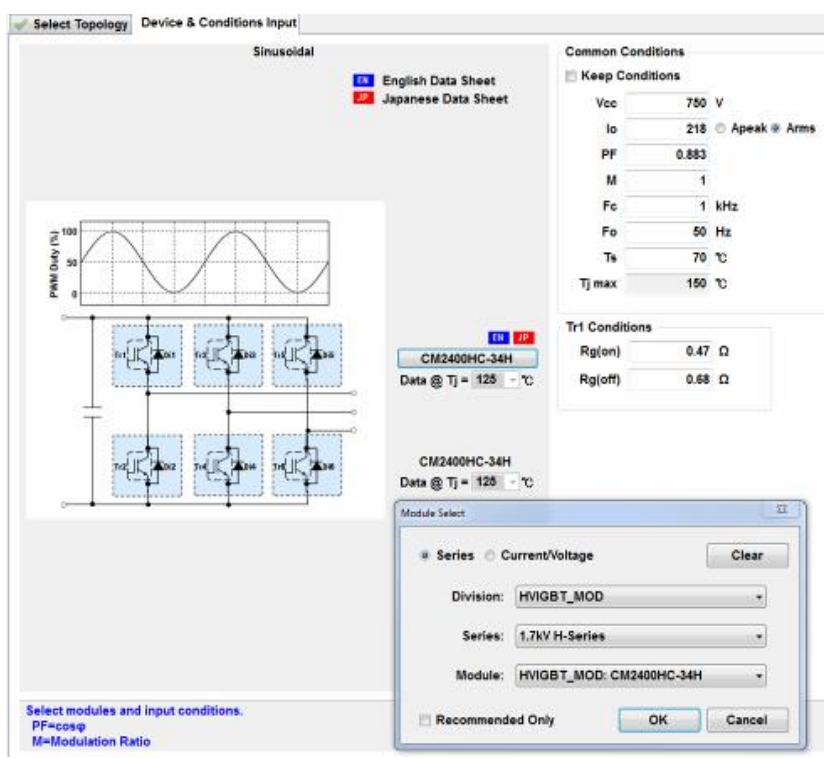

Fig. 4 The „Device \& Components” screen for IGBT module testing at the rated condition operation.

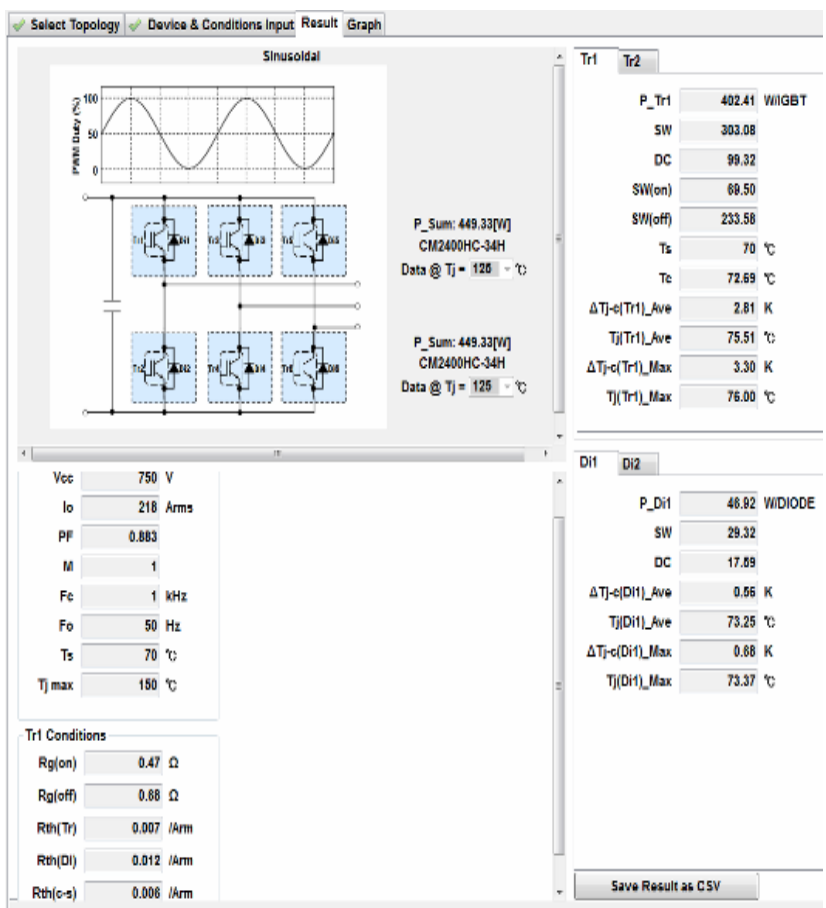

Fig. 5 "Result" screen with the characteristic values for the semiconductor components corresponding to a phase of the inverter.

The following parameters for the operation at rated load values have been introduced (Fig. 4 and Fig. 5):

- $\quad$ Input voltage $V c c\left(\mathrm{U}_{\text {ININV1 } 1}\right)=750 \mathrm{~V}$;

- $\quad$ Output rated current $I o\left(\mathrm{I}_{\mathrm{NMAS} 1}\right)=218 \mathrm{~A}_{\mathrm{RMS}}$;

- $\quad$ Machine power factor $P F\left(\cos \varphi_{\mathrm{NMAS} 1}\right)=0.883$

- Modulation factor $M=1$.

- $\quad$ Switching frequency $F c=1 \mathrm{kHz}$;

- $\quad$ Converter output frequency $F c=50 \mathrm{~Hz}$;

- Heat sink temperature Ts $=70{ }^{\circ} \mathrm{C}$.

The following considerations were considered in order to choose the gate control resistances which are relevant for the turn on and for the turn off process of the IGBT transistors, respectively:

- achieving minimal switching losses in both turn on and turn off by choosing the lowest possible resistance values;

- the peak current of the gate control devices.

The following values have been chosen using the data sheets:

- conduction input resistance $\mathrm{R}_{\mathrm{g}(\mathrm{ON})}=0.47 \Omega / 1 \mathrm{~W}$;

- blocking resistance $\mathrm{R}_{\mathrm{g}(\mathrm{Off})}=0.68 \Omega / 1 \mathrm{~W}$.

\section{Choosing The CoOling SYSTEM}

The heat transfer diagram (Fig. 6) can be drawn up with the values obtained in the "Result" screen [11].

The "Graph" screen can generate the dissipated power versus time characteristic for two modules belonging to the same phase, giving additional information when multiple capsules are mounted on the same heat sink (Fig. 7). 


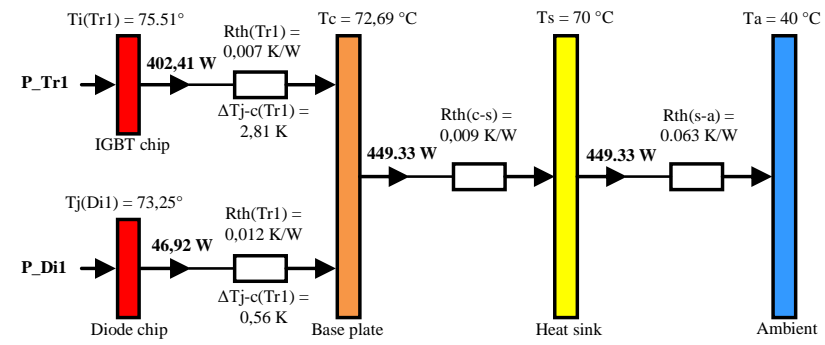

Fig. 6 The heat transfer diagram for the chosen IGBT module.

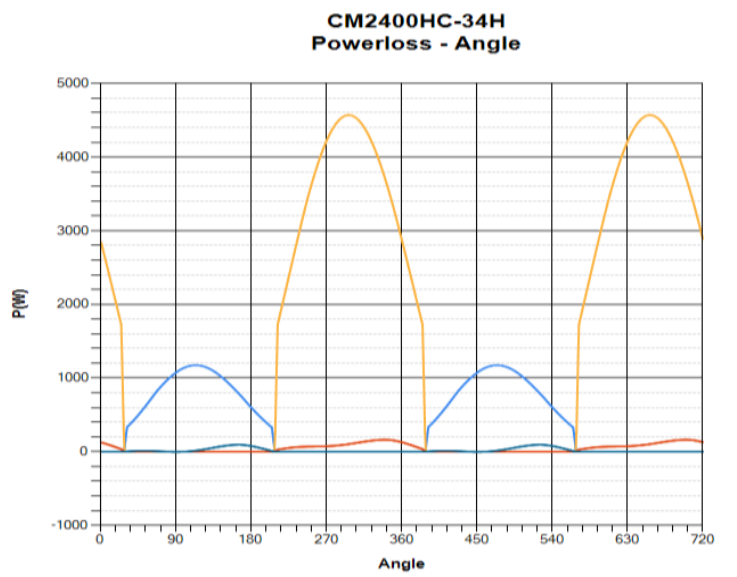

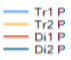

Fig. 7 Power dissipation versus time dependence for modules 1 and 2 of the inverters.

The heat transfer resistance between ambient and heat sink is:

$$
R t h_{s-a}=\frac{T_{c}-T_{a}}{p S u m}-R t h_{c-s}=0.063 \mathrm{~K} / \mathrm{W},
$$

where:

$T_{c} \quad$ - case temperature;

$T_{a} \quad$ - ambient temperature;

$P \_S u m$ - total power dissipated by the module due to the conduction and commutation losses.

A heat sink is chosen from the catalog in order to meet the condition:

$$
R t h_{s-a} c a t<R t h_{s-a} c a l c,
$$

where:

$R t h_{s-a}$ calc - calculated thermal resistance heat sink ambient;

$R t h_{s-a} c a t$ - thermal resistance heat sink - ambient catalog value.

A heat sink with the profile shown in Fig. 8 having a length of $250 \mathrm{~mm}$, manufactured by MECCAL type P200 83 was chosen [12].

From the thermal transfer curves shown in Fig. 9, it can be seen that, provided an air speed of Vair $=7.2 \mathrm{~m} / \mathrm{s}$ through the heatsink with a length of $250 \mathrm{~mm}$, the following resistance is obtained:

$$
\text { Rth }_{s-a} c a t=0.051 \mathrm{~K} / \mathrm{W},
$$

which is less than the value in (22), so the cooling system is chosen properly.

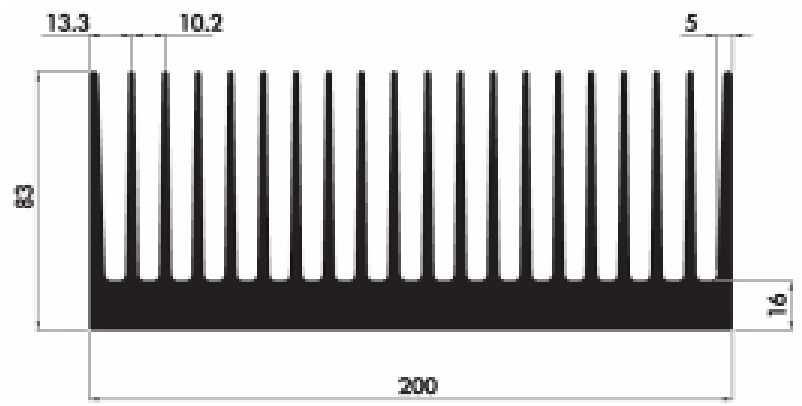

Fig. 8 Transversal section through the heat sink.

\section{Thermal Resistance - Forced convection}

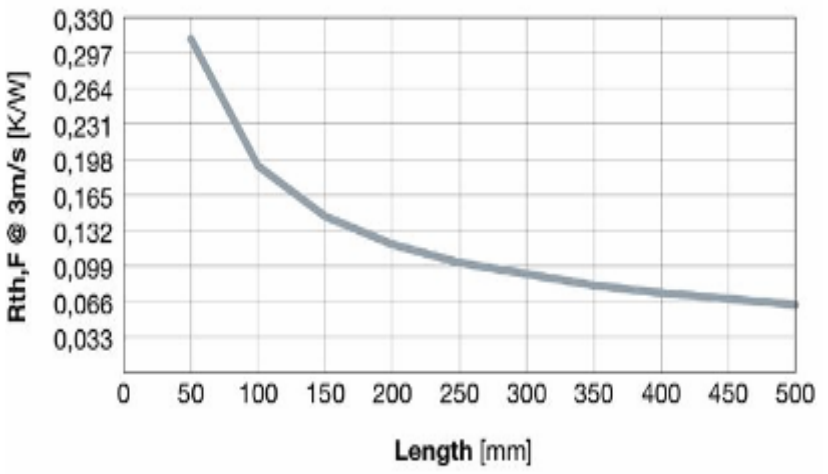

Air speed correction factor

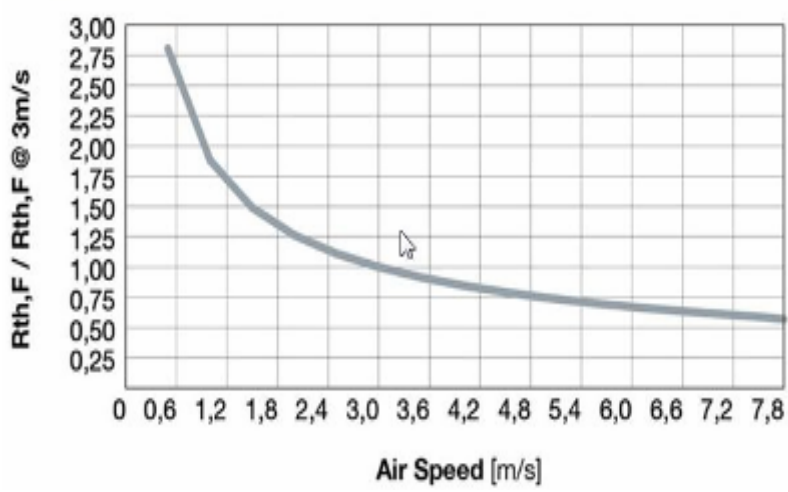

Fig. 9 The thermal transfer curves for the P200 83 heat sink

\section{The Choise of The Power CABles}

The following characteristics of the inverters must be taken into account when dimensioning the cables:

- $\quad$ application: railway inverters;

- $\quad$ input voltage: $900 \mathrm{Vdc}$;

- rated current: $218 \mathrm{~A}$;

- overload current: 327 A.

The cables used for railway rolling stock comply with the standard SR EN 50355:2014 "Railway applications Railway rolling stock cables having special fire performance - Guide to use" [13].

The size of the cable section must be chosen from the standardized cable sections. When choosing the conductor section, the following factors will be taken into account:

- Electrical stresses in insulation, which are due to the operating voltage; 
- Electrical stresses due to the intensity of the current flowing through the circuit and which must be lower than those allowed;

- Thermal stresses of the cables due to long-term, overload or short-circuit currents, taking into account the values indicated by the manufacturer and the application of the correction coefficients due to the positioning of the cables during installation as well as the maximum ambient operating temperatures.

The range of HELUTHERM 145 cables produced by HELUKABEL meets the required conditions [14].

Fig. 10 shows the catalog sheet for this type of cables and in Fig. 11 is figured the table of allowed currents and correction coefficients.

According to the catalog sheet, the selection criteria are met as follows:

- Electrical stresses in insulation, which are due to the operating voltage:
- $\quad$ for cables up to $1 \mathrm{~mm}^{2} U_{d} / U 300 / 500 \mathrm{~V}$;

- for cables from $1.5 \mathrm{~mm}^{2} U_{0} / U 450 / 750 \mathrm{~V}$;

- at fixed and protected installation from $1.5 \mathrm{~mm}^{2} U_{0} / U 600 / 1000 \mathrm{~V}$.

- Electrical stresses due to current intensity in the case of outdoor positioning:

- for outdoor wiring situation $70 \mathrm{~mm}^{2}$ cable supports a current of $391 \mathrm{~A}$, bigger than overload current $-327 \mathrm{~A}$

Cables with the following codes were chosen:

- $51476-70 \mathrm{~mm}^{2}$ black cable;

- $51340 \quad-2.5 \mathrm{~mm}^{2}$ red cable;

- 51338 - $2.5 \mathrm{~mm}^{2}$ blue cable;

- $51298-0.75 \mathrm{~mm}^{2}$ red cable izolated in SCSI tube;

- $51296-0.75 \mathrm{~mm}^{2}$ blue cable izolated in SCSI tube.

\section{HELUTHERM 145 flexible, cross-linked, halogen-free}
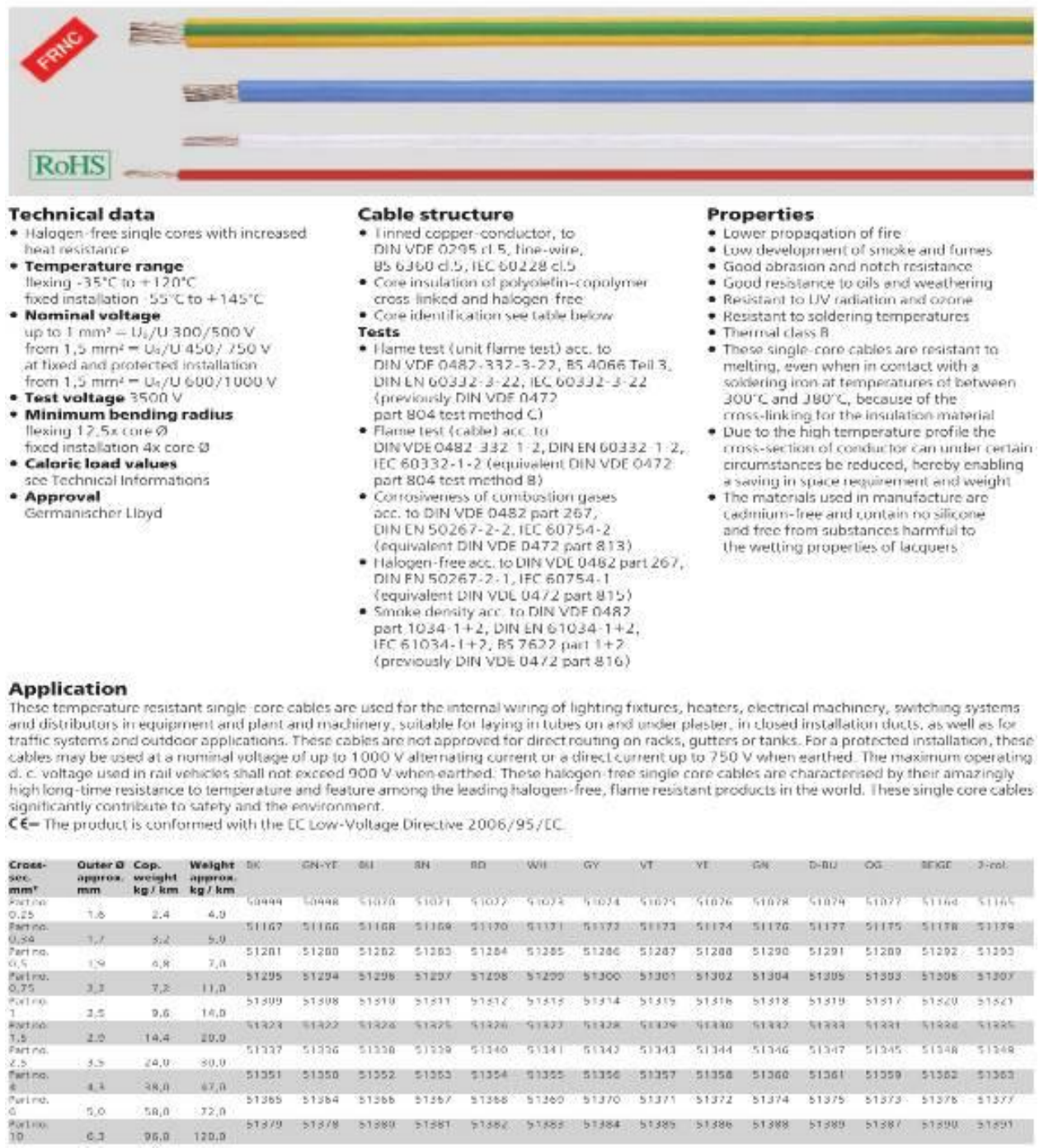

Fig. 10 HELUTHERM 145 cable catalog sheet. 
CURRENT RATINGS FOR HELUTHERM ${ }^{\circledR} 145$

Operting temperature at conductor $120^{\circ} \mathrm{C}$
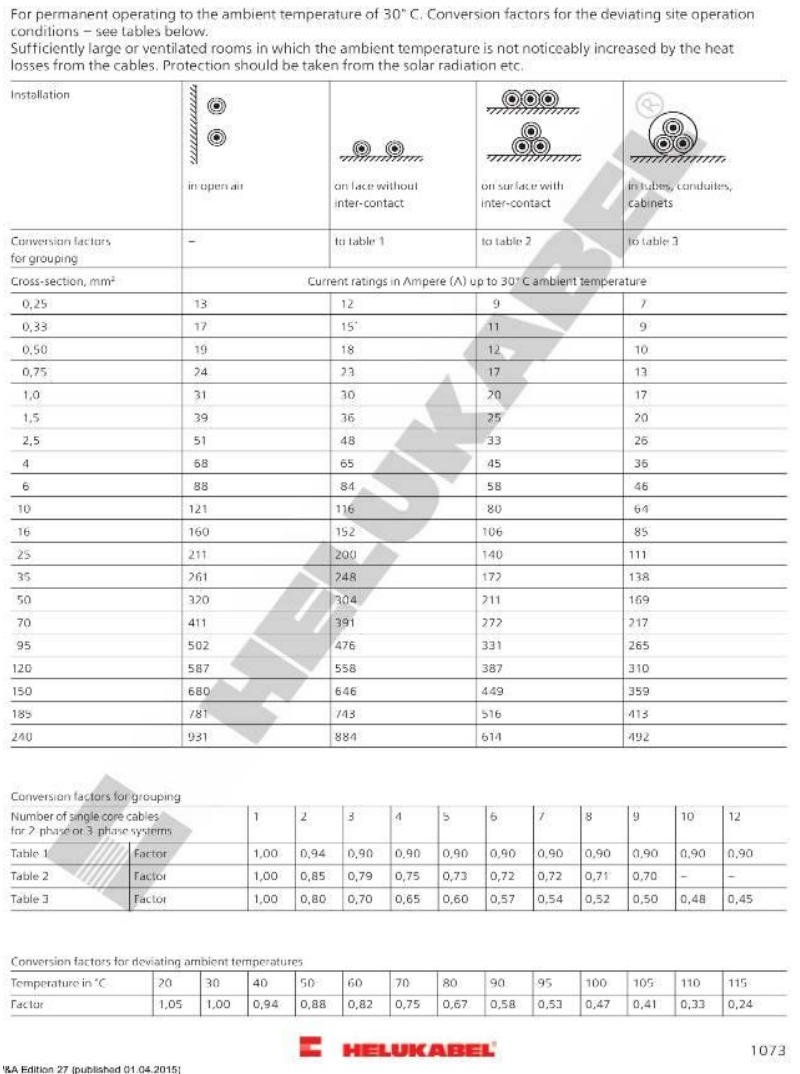

Fig. 11 Current ratings for HELETHERM 145.

\section{CONCLUSIONS}

The research conducted in this paper highlights the fact that when choosing the force components for a test experimentation bench designed to test various control strategies for traction converters, it is necessary to consider the addition of bigger safety coefficients than usual at their technical characteristics covering some control errors which may occur. It has also been shown that a forced ventilation cooling system is suitable, cheaper and less complex than a liquid cooling one.

\section{ACKNOWLEDGMENT}

This work was supported by the grant POCU380/6/13/123990, co-financed by the European Social Fund within the Sectorial Operational Program Human Capital 2014 - 2020.

Source of research funding in this article: grant POCU380/6/13/123990.
Contribution of authors:

First author $-50 \%$

First coauthor $-30 \%$

Second coauthor $-20 \%$

Received on August 10,2021

Editorial Approval on November 30, 2021

\section{REFERENCES}

[1] X. Huang, W. Chang and T. Q. Zheng, "Study of the protection and driving characteristics for high voltage high power IGBT modules used in traction convertor," 2015 IEEE 10th Conference on Industrial Electronics and Applications (ICIEA), Auckland, New Zealand, 2015, pp. 1330-1334.

[2] M. M. Bakran, H. Eckel, M. Helsper and A. Nagel, "Next Generation of IGBT-Modules Applied to High Power Traction," 2007 European Conference on Power Electronics and Applications, Aalborg, Denmark, 2007, pp. 1-9.

[3] K. Sheng, B.W. Williams, X. He, Z. Qian, S.J. Finney, "Measurement of IGBT switching frequency limits," Power Electronics Specialists Conference, 1999, PESC 99. 30 ${ }^{\text {th }}$ Annual IEEE.

[4] S. C. Das, A. Tiwari, G. Narayanan and A. K. Kumar, "Experimental investigation on switching characteristics of IGBTs for traction application," 2012 IEEE International Conference onPower Electronics, Drives and Energy Systems (PEDES), Bengaluru, India, 2012, pp. 1-5.

[5] M. B. Inarra, I.B. Zubiaurre, I.L.Bengoetxea, I.Z. Azaceta, "Power Electronic converter. Design Book".

[6] L. S. Goreci, M. Popescu and I. Tilă, "The choice of the IGBTs and their cooling in electric traction converters for autonomous vehicles," 2021 International Conference on Applied and Theoretical Electricity (ICATE), Craiova, Romania, 2021, pp. 1-5.

[7] M. Popescu, A. Bitoleanu, D. Mihai, C. Constantinescu, "Convertoare statice si structuri de comandă performante", Editura Sitech, 2000

[8] AVX: Medium Power Film Capacitors, Application Notes

[9] Mitsubishi HVIGBT Modules CM2400HC-34H, https://www. mitsubishielectric-mesh.com/products/pdf/cm2400hc-34h_e.pdf.

[10] Simulation soft, Mitsubishi Electric Power Module Loss Simulator, http://sem.mitsubishielectric.eu/products/power_semiconductors/m $\underline{\text { elcosim }}$

[11] R. Künzi, "Thermal design of power electronic circuits," CERN Yellow Report CERN-2015-003, pp.311-327.

[12] Air cooled technologies. Heat sinks catalogue, http://www.meccal. com/en/download/catalogo-prodotti-aria.pdf.

[13] SR EN 50355:2014 "Railway applications - Railway rolling stock cables having special fire performance - Guide to use"

[14] Helutherm 145 Cable https://helukabel-sea.com/wpcontent/uploads/2018/07/HELUTHERM\%C2\%AE-145.pdf 